\title{
HIGHLY EFFICIENT PURIFICATION OF FINELY DISPERSED OIL CONTAMINATED WATERS BY COAGULATION/FLOCCULATION METHOD AND EFFECTS ON MEMBRANE FILTRATION
}

\author{
GÁBOR VERÉB ${ }^{a^{*}}$, LILLA NAGYa, SZABOLCS KERTÉSZ ${ }^{a}$, \\ ILDIKÓ KOVÁCS ${ }^{a}$, CECILIA HODÚR ${ }^{a}$, ZSUZSANNA LÁSZLÓa
}

\begin{abstract}
In the present study the purification of finely dispersed oil contaminated water (100 ppm crude oil; $\mathrm{d}_{\text {oil droplets }}<2 \mu \mathrm{m}$ ) was investigated by using coagulation/flocculation process, membrane separation and combined methods. As coagulant, polyaluminum chloride (Bopac) iron(III) chloride and aluminum(III) chloride, while as flocculant anionic polyelectrolyte were applied. For the membrane separation, hydrophilic polyethersulfone (PES) microfilter $(\mathrm{d}=0.2 \mu \mathrm{m})$ was used, while for the determination of the purification efficiencies turbidity, chemical oxygen demand and extractable oil content were measured. The utilization of Bopac polyaluminum chloride coagulant (by setting $\mathrm{Al}^{3+}$ content to $20 \mathrm{ppm}$ ) resulted in high purification efficiency $(96.7 \%)$. The extra addition of $1 \mathrm{ppm}$ anionic polyelectrolyte lead to the increase in efficiency up to $98.8 \%$. Due to the effective destabilization of oil in water emulsion the flux highly increased during the microfiltration of the emulsion, since both irreversible and reversible membrane resistances were greatly reduced.
\end{abstract}

Keywords: oil contaminated waters, coagulation, flocculation, Bopac, membrane filtration

\section{INTRODUCTION}

Large amount of oil contaminated waters are produced by many industrial processes, including food processing, petrochemical industries, metal industry and oily contaminants can appear in ground waters as well [1-6].

\footnotetext{
a Department of Process Engineering, Faculty of Engineering, University of Szeged, $\mathrm{H}-6725$ Szeged, Moszkvai krt. 9., Hungary

* Corresponding author: verebg@mk.u-szeged.hu
} 
For the elimination of oily pollutants of waters, the most common processes are gravity separation, centrifugation [7], skimming [8], flotation [9], thermal process [10], adsorption [6] and chemical destabilization [2, 5, 7, 10-12]. These traditional methods are sufficiently effective in case of free (or floating) oil $\left(\mathrm{d}_{\text {oil droplets }}>150 \mu \mathrm{m}\right)$ and in case of coarse dispersions. However, oil in water emulsions (which is characterized in the literature by droplets smaller than $20 \mu \mathrm{m}$ ) and "dissolved oils" (when droplets are smaller than $5 \mu \mathrm{m}$ ) require to develop more effective destabilization methods and/or more effective water treatment processes [3, 13-17].

Membrane separation (micro- $[15,17-25]$ and ultrafiltration $[13,18$, 23, 26-29]) can also be efficient for the treatment of these kind of water pollutants, however membrane fouling $[10,30]$ is a general problem (not only in case of oily contaminants), which inhibit the economic utilization in many cases. Microfilters have relatively higher fluxes compared to ultrafiltration, but the latter results in higher purification efficiency. To reduce fouling, highly hydrophilic membranes [25, 31, 32] can be used (in case oil in water emulsions), or membrane separation can be combined with other methods such as gas injection [33], ozonation [34, 35] or destabilization [5, 36]. In the recent study of $\mathrm{M}$. Matos et al. [5] destabilization/centrifugation/ultrafiltration hybrid process was applied with high efficiency $(97.4 \%)$ to purify oil in water emulsion, using calcium chloride coagulant and $\mathrm{ZrO}_{2}$ ceramic ultrafilter (300 $\mathrm{kDa}$ ) membrane. Their results are very promising, however the utilization of microfilter membranes (in order to achieve relatively higher fluxes) can be more preferable if the destabilization method is effective enough to allow its utilization with similarly high purification efficiency.

In the present study finely dispersed oil $\left(\mathrm{d}_{\text {oil droplets }}<2 \mu \mathrm{m}\right)$ contaminated water was purified with destabilization, and the effect of pretreatment on membrane microfiltration was investigated.

For the destabilization of the emulsion polyaluminum chloride was used as coagulant. Polyaluminum chlorides are extensively used in water and waste water treatments, which have several beneficial properties in comparison with conventional aluminum chloride such as higher removal efficiency, lower $\mathrm{pH}$ sensitivity and lower residual $\mathrm{Al}^{3+}$ content $[11,12]$. Polyaluminum chlorides contain $\mathrm{Al}_{2}(\mathrm{OH})_{2}{ }^{4+}, \mathrm{Al}_{8}(\mathrm{OH})_{20^{4+}}, \mathrm{AlO}_{4} \mathrm{Al}_{12}(\mathrm{OH})_{24}\left(\mathrm{H}_{2} \mathrm{O}\right)_{12^{7+}}$ and other species [11, 37]. $\mathrm{AlO}_{4} \mathrm{Al}_{12}(\mathrm{OH})_{24}\left(\mathrm{H}_{2} \mathrm{O}\right)_{12}{ }^{7+}$ (generally referred as $\mathrm{Al}_{13}$ ) has been reported as the most effective species of polyaluminum chlorides, which has a pre-hydrolyzed structure with high positive charge $\left(\mathrm{Al}_{13^{7+}}\right)$ making it less sensitive to $\mathrm{pH}$ changes [11, 38-40]. $\mathrm{Al}_{13}$ can be described by the Keggin structure: The central tetrahedral $\mathrm{AlO}_{4}$ unit is surrounded by octahedral $\mathrm{AlO}_{6}$ units. This structure allows the molecule to hydrate and dehydrate without significant structural changes. These $\mathrm{Al}_{13}$ units can connect at the peaks and edges of octahedrals creating long chains which contain hydroxyl functional groups and cause high adsorption efficiency resulting in high elimination performance of colloid pollutants. 
Since polyethersulfone is one of the most extensively used material to produce nano-, ultra-, and microfilter membranes [4, 23, 24, 41], because of its chemical- and thermal stability, easy processing and environmental endurance $[4,42]$, therefore in the present study polyethersulfone microfilter was used to eliminate the oily contaminants with and without the destabilization pretreatment. Permeate fluxes, resistances, fouling models and purification efficiencies were investigated in both cases.

\section{RESULTS AND DISCUSSION}

\section{Destabilization of finely dispersed oil in water emulsion}

In the first step Bopac was added into the emulsion in 6 different amounts which resulted in 2, 5, 10, 15, 20 and $40 \mathrm{ppm} \mathrm{Al}^{3+}$ content in the total volume. After 30 min sedimentation, the turbidity of the supernatants was measured and the purification efficiencies (Figure 1) were calculated from the initial turbidities $(155 \pm 5)$.

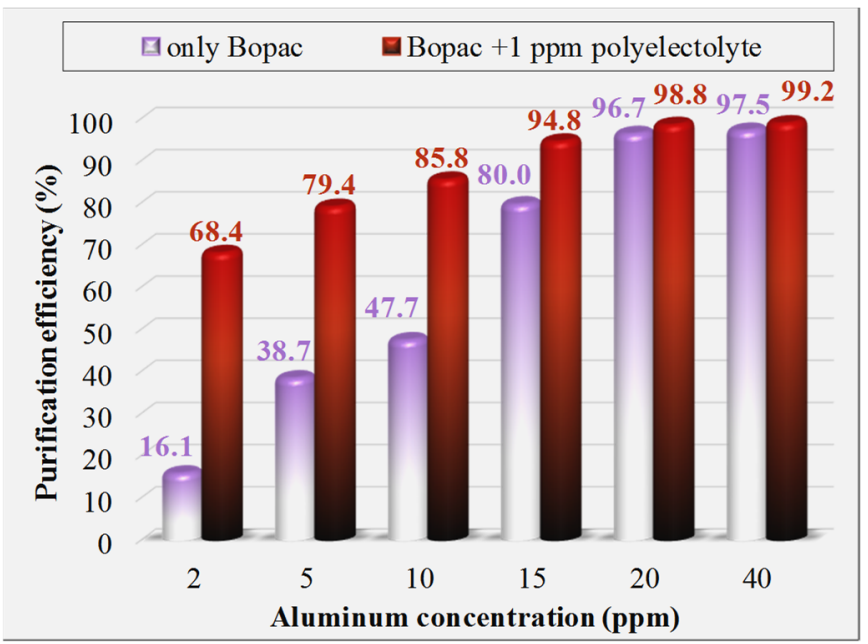

Figure 1. Purification efficiencies (calculated from turbidity values) in case of different Bopac coagulant dose (resulted 2, 5, 10, 15, 20 and 40 ppm aluminum content) with and without the addition of $1 \mathrm{ppm}$ anionic polyelectrolyte flocculant.

As it can be seen in Figure 1 higher coagulant dose resulted in increased purification efficiencies. It should be noted that in case of lower aluminum doses (2, 5 and $10 \mathrm{ppm} \mathrm{Al}{ }^{3+}$ content) the created flakes were floating in the treated emulsions because of the very similar density of the flakes to water due to the low 
density of original oil droplets $(\sim 0.73 \mathrm{~g} / \mathrm{mL})$. At higher aluminum doses $(15,20,40$ $\mathrm{ppm}$ ), the flakes were easily sedimented. $20 \mathrm{ppm}$ aluminum concentration resulted in $96.7 \%$ purification efficiency, while double dose increased this value up to $97.5 \%$, but this high concentration is not recommended because of the double amount of sediment.

Experiments were also carried out by the further addition of $1 \mathrm{ppm}$ anionic polyelectrolyte to the emulsion as flocculant. In this series similar tendency was observed, however purification efficiencies were higher in all cases compared to the results in the absence of anionic polyelectrolyte (see Figure 1). By the utilization of flocculant the produced flakes were much bigger than in the absence of the polyelectrolyte, therefore the flakes sedimented much faster in case of 15,20 and $40 \mathrm{ppm}$ aluminum doses. At lower aluminum content $(2,5$ and $10 \mathrm{ppm})$ the flakes were floating in this case as well. $20 \mathrm{ppm}$ aluminum concentration with the simultaneous utilization of $1 \mathrm{ppm}$ anionic polyelectrolyte resulted in $98.8 \%$ purification efficiency. However, doubled dose of aluminum (40 ppm) resulted in a marginally higher purification efficiency $(99.2 \%)$ again, but the sediment volume was much higher in this case as well. Based on the achievable purification efficiencies and the sedimentation tendencies (see Figure 2), 20 ppm aluminum concentration and the extra addition of $1 \mathrm{ppm}$ anionic polyelectrolyte can be beneficial.

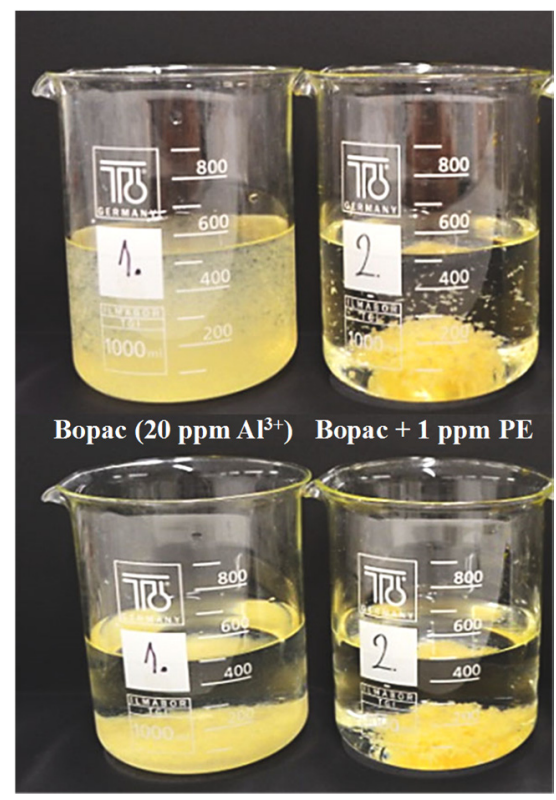

Figure 2. Sedimantation of the destabilized oil in water emulsion by Bopac coagulant (20 ppm aluminum content) and by the further addition of $1 \mathrm{ppm}$ anionic polyelectrolyte. Top row: after 30 sec sedimentation; bottom row: after 30 min sedimentation. 
Purification efficiencies were determined by measuring COD and extractable oil content as well (over the turbidity) when $20 \mathrm{ppm}$ aluminum was applied with or without the utilization of $1 \mathrm{ppm}$ anionic polyelectrolyte. Results are shown in Figure 3.

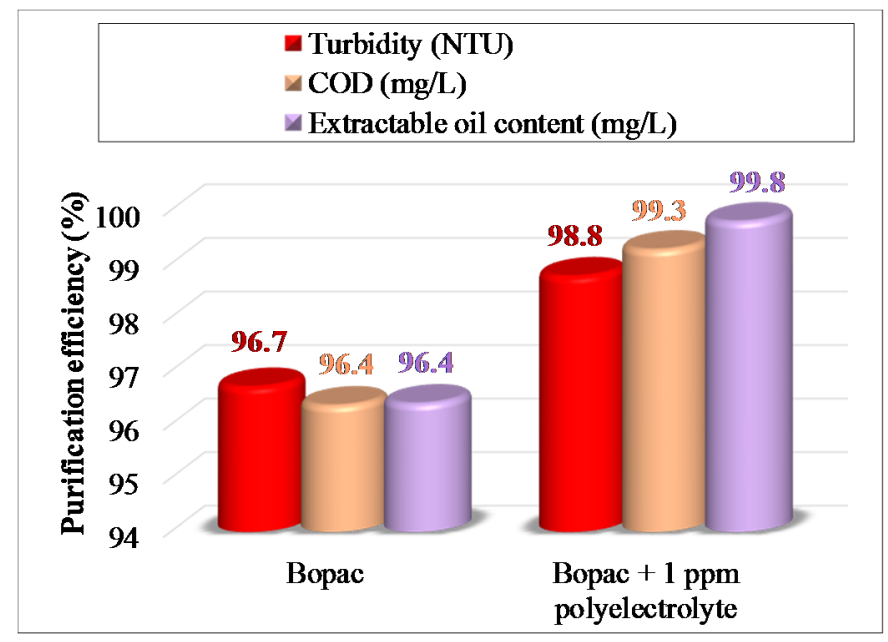

Figure 3. Purification efficiencies - calculated from turbidity, $C O D$ value and extractable oil content - in case of $20 \mathrm{ppm}$ aluminum content with and without the addition of $1 \mathrm{ppm}$ anionic polyelectrolyte flocculant.

Without the utilization of polyelectrolyte, the COD and extractable oil content eliminations are slightly smaller $(96.4 \%)$ than colloid elimination $(96.7 \%$ - determined by turbidity measurements) because of the small amount of water-soluble organic compounds. When the polyelectrolyte was also used, the determined COD and extractable oil content eliminations were higher (99.3 and 99.8\%), which presumably due to the more effective adsorption of water-soluble organic compounds onto the flakes formed by the polyelectrolyte. These results also confirmed the beneficial utilization of $1 \mathrm{ppm}$ anionic polyelectrolyte flocculant.

Additionally, conventional iron(III) chloride and aluminum(III) chloride were also applied as reference coagulants in calculated amounts, to set the $\mathrm{Fe}^{3+}$ or $\mathrm{Al}^{3+}$ concentration similarly to $20 \mathrm{ppm}$. Based on turbidity measurements iron(III) chloride resulted in a very low purification efficiency $(33 \%)$ while aluminum(III) chloride was more efficient $(72 \%)$, although to a substantially lower degree compared to the efficiency of polyaluminum chloride $(96.7 \%)$ The outstanding purification efficiency of Bopac polyaluminum chloride can be explained 
by its pre-hydrolyzed form, the high basicity, and by the Keggin structure, which can results in higher adsorption ability compared to conventional aluminum coagulants.

\section{Membrane microfiltration of finely dispersed oil in water emulsion}

Finely dispersed oil in water emulsion was filtered by a polyethersulfone membrane microfilter $\left(d_{\text {pore }}=0.2 \mu \mathrm{m}\right)$, with and without the destabilization of the emulsion. In case of destabilization pretreatment, Bopac (20 ppm aluminum content) and anionic polyelectrolyte (1 ppm) were also used. The measured flux declines are presented in Figure 4. It can be seen, that in case of not pretreated oil in water emulsion the flux was rapidly and immensely declining, while in case of pretreated (destabilized) emulsion much higher flux was measured. Therefore, the total filtration time (until the $V R R=5$ filtration ratio) was only $406 \mathrm{~s}$ in case of the destabilized emulsion, while $5493 \mathrm{~s}$ in case of not-pretreated emulsion.

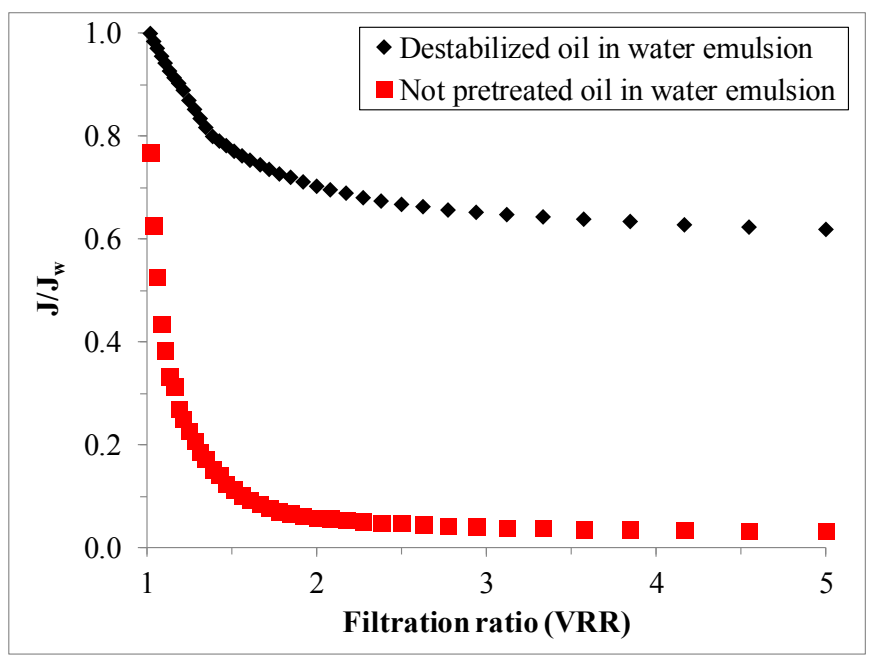

Figure 4. Measured fluxes during membrane microfiltration $\left(P E S-d_{\text {pore }}=0.2 \mu \mathrm{m}\right.$ ) of oil in water emulsion with and without destabilization pretreatment

(destabilization was carried out with Bopac - resulting 20 ppm aluminum content - and $1 \mathrm{ppm}$ anionic polyelectrolyte).

Based on the calculations which are described in the "Experimental" section, in the "Resistance-in-series model" chapter, the different resistances were determined in both cases of filtrations. Results are presented in Figure 5, 
which demonstrates that the total resistance was $\sim 96 \%$ lower in case of destabilized oil in water emulsion compared to the flux of not pretreated emulsion. Both irreversible- and reversible membrane resistances were also significantly reduced by the used destabilization pretreatment.

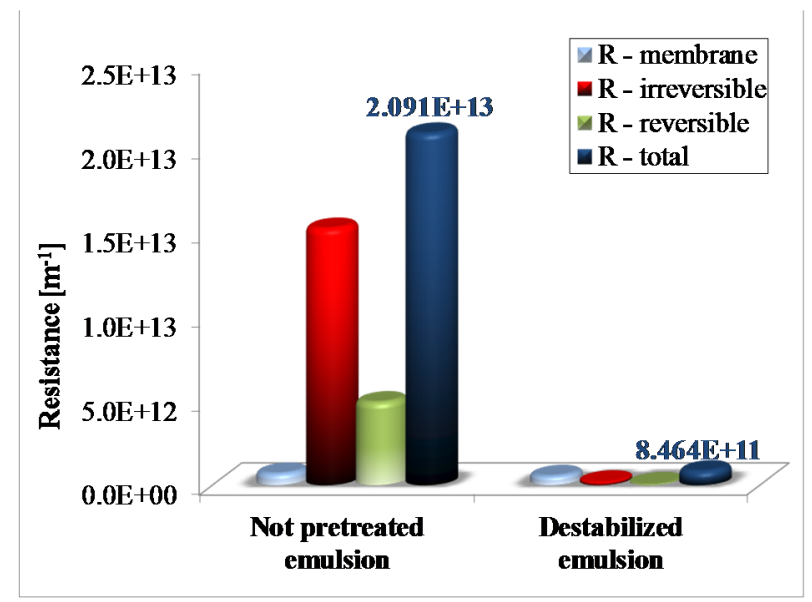

Figure 5. Different resistances in case of not pretreated and destabilized emulsion during the microfiltration.

Purification efficiency was $98 \%$ in case of not pretreated emulsion and $99 \%$ in case of destabilized emulsion (based on measured COD values), which means that the investigated oil in water emulsion can be effectively purified by membrane microfiltration without any pretreatment, but filtration resistances can be significantly reduced with the described destabilization method.

Additionally, widely used fouling models such as complete pore blocking-, gradual pore blocking-, intermediate filtration- and cake filtration models [38] were fitted onto the measured flux curves and it was found that both with or without the destabilization pretreatment the filtrations can be described mostly by the cake filtration model.

Comparing our results with the recent results of $\mathrm{M}$. Matos et al. [5] (they applied destabilization/ultrafiltration $(300 \mathrm{kDa})$ hybrid process with a 97.4\% purification efficiency using calcium chloride coagulant and $\mathrm{ZrO}_{2}$ ceramic ultrafilter) it can be concluded, that using polyaluminum chloride and anionic polyelectrolyte similarly very high purification efficiency can be achieved. Destabilized emulsion can be filtered with high flux and with high elimination efficiency by a microfilter, therefore the utilization of ultrafiltration is not necessary. 


\section{CONCLUSIONS}

Bopac polyaluminum chloride successfully destabilized finely dispersed oil in water emulsions $\left(\mathrm{d}_{\text {oil droplets }}<2 \mu \mathrm{m}\right.$ ) with high efficiency, without any additional flocculant, due to the high basicity, the pre-hydrolyzed form and the Keggin structure. The efficient doses are not lower than $15 \mathrm{ppm}$ aluminum concentration (in case of $100 \mathrm{ppm}$ oil content) since below this concentration the flakes were floating because of their low density. $20 \mathrm{ppm}$ aluminum concentration resulted in $96.7 \%$ purification efficiency, while with the further addition of $1 \mathrm{ppm}$ anionic polyelectrolyte the efficiency increased up to $98.8 \%$, and the sedimentation ability was also significantly increased by the added flocculant.

The investigated finely dispersed oil in water emulsion can be effectively purified by membrane microfiltration without any pretreatment, but both irreversible- and reversible filtration resistances can be significantly reduced with the described destabilization method.

\section{EXPERIMENTAL SECTION}

\section{Preparation of finely dispersed oil in water emulsion}

Finely dispersed oil in water emulsion ( $\mathrm{C}_{\text {oil }}=100 \mathrm{ppm}$; $\mathrm{d}_{\text {oil droplets }}=100-2000$ $\mathrm{nm}$ ) was prepared in two steps using crude oil (from Algyö, Hungary; supported by $M O L$ Zrt.). Firstly $1 \mathrm{wt}$.\% emulsion was prepared by intensive stirring (35000 $\mathrm{rpm}$ ), then $5 \mathrm{~mL}$ of this emulsion was inoculated into $495 \mathrm{~mL}$ of model ground water directly below the transducer of an ultrasonic homogenizer (Hielscher UP200S). The duration of homogenization was 10 minutes, maximal amplitude and cycle was applied and the emulsion was thermostated to $25^{\circ} \mathrm{C}$.

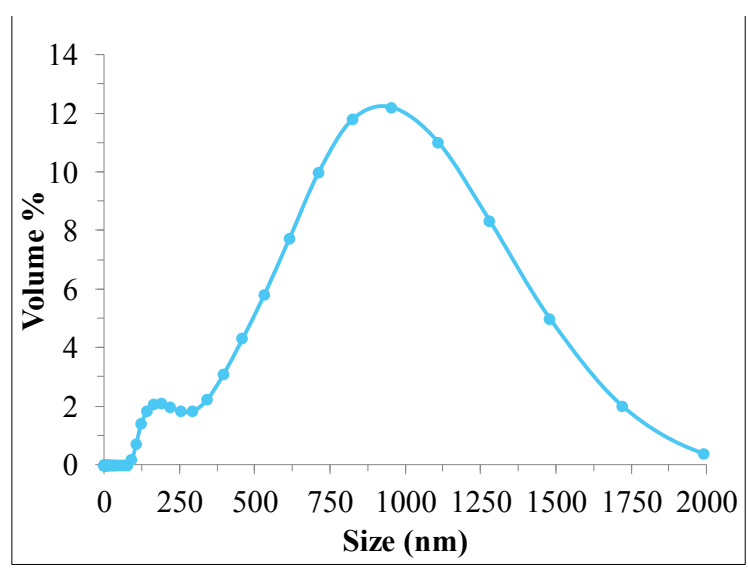

Figure 6. Size distribution of the investigated finely dispersed oil in water emulsion. 
The investigated water was a model of real groundwater located in south Hungary, which contained the following salts: $2.26 \mathrm{~g} / \mathrm{L} \mathrm{NaHCO} ; 53.4 \mathrm{mg} / \mathrm{L}$ $\mathrm{NH}_{4} \mathrm{Cl} ; 19.1 \mathrm{mg} / \mathrm{L} \mathrm{CaCl} 2 ; 20.9 \mathrm{mg} / \mathrm{L} \mathrm{KCl} ; 93.5 \mathrm{mg} / \mathrm{L} \mathrm{NaCl} ; 4.5 \mathrm{mg} / \mathrm{L} \mathrm{FeCl} 3$ and $35.1 \mathrm{mg} / \mathrm{L} \mathrm{MgSO}_{4}$ (Sigma Aldrich; analytical grade). The size distribution of the oil droplets in the produced emulsion was described by dynamic light scattering using a Malvern ZetaSizer4 type equipment (Figure 6).

\section{Destabilization experiments}

Coagulation/flocculation experiments were carried out in a four-backer Jar Test flocculator (VELP Scientifica) at room temperature. Coagulants and flocculant were added during intensive stirring (200 rpm); after 30 s homogenization 2 min slow stirring (20 rpm) was applied, then the formed flakes were left to settle for $30 \mathrm{~min}$. As highly efficient coagulant a polyaluminum chloride (named as "Bopac", produced by Unichem Kft.- Hungary) was used, while as reference coagulants iron(III) chloride, and aluminum(III) chloride (named as "Unifloc-C" and "Unipac" respectively; produced by Unichem Kft.- Hungary) were used. Bopac is an $\mathrm{ACH}$ type pre-hydrolyzed polyaluminum chloride which allowed in drinking water production with high basicity $(82.0 \pm 2 \%)$ and with an $\mathrm{n}_{\mathrm{Al}}: \mathrm{n}_{\mathrm{Cl}}=2.0 \pm 0.2$ ratio. Enhanced flocculation was carried out by further addition of an anionic polyelectrolyte flocculant (named as "Unifloc LT 27"; produced by Unichem Kft.Hungary).

\section{Membrane filtration}

Membrane filtration experiments were carried out in a batch-stirred membrane reactor (Millipore XFUF07601; produced by New Logic Research Inc.) equipped with a hydrophilic polyethersulfone (PES) microfilter membrane $\left(d_{\text {pore }}=0.2 \mu \mathrm{m}\right.$; filtration area was $\left.0.00332 \mathrm{~m}^{2}\right)$. The applied transmembrane pressure was $0.1 \mathrm{MPa}$ (provided by nitrogen gas). The volume of the treated emulsion was $250 \mathrm{~mL}$ and filtration was carried out until $200 \mathrm{~mL}$ of permeate was produced $(\mathrm{VRR}=5)$.

\section{Determination of purification efficiency}

Purification efficiencies were determined by measuring turbidity (Hach $2100 N$ ) and in some cases chemical oxygen demand (COD) and extractable oil content (TOG/TPH). COD values were measured by the standard potassium dichromate oxidation method using standard test tubes (Hanna Instruments) and applying digestions for $120 \mathrm{~min}$ at $150^{\circ} \mathrm{C}$ in a Lovibond ET 108 type COD digester. The COD values were measured with a Lovibond $C O D$ Vario type COD photometer. Extractable oil content was measured by a Wilks InfraCal TOG/TPH type analyzer, using hexane as extracting solvent.

The purification efficiency $(R)$ was determined as: 


$$
R=\left(1-\frac{a}{a_{0}}\right) \cdot 100 \%
$$

where $a_{0}$ is the turbidity, COD, or TOG/TPH values of the feed while a indicates the values of the permeate.

\section{Resistance-in-series model}

The membrane resistance $\left(R_{M}\right)$ was calculated as [43]:

$$
\mathrm{R}_{\mathrm{M}}=\frac{\Delta \mathrm{p}}{\mathrm{J}_{\mathrm{w}} \eta_{\mathrm{w}}} \quad\left[\mathrm{m}^{-1}\right]
$$

where $\Delta p$ is the transmembrane pressure $(\mathrm{Pa}), J_{w}$ is the water flux of the clean membrane and $\eta_{w}$ is the viscosity of the water (Pas).

The irreversible resistance $\left(R_{\text {/rrev }}\right)$ was determined by re-measuring the water flux on the used membrane after the filtration, followed by a purification step (intensive rinsing with distilled water):

$$
\mathrm{R}_{\text {Irrev }}=\frac{\Delta \mathrm{p}}{\mathrm{J}_{\mathrm{WA}} \eta_{\mathrm{w}}}-\mathrm{R}_{\mathrm{M}} \quad\left[\mathrm{m}^{-1}\right]
$$

where $J_{W A}$ is the water flux after the cleaning procedure.

The reversible resistance $\left(R_{R e v}\right)$, caused by not adhered contaminants and concentration polarisation layer can be calculated as:

$$
\mathrm{R}_{\mathrm{Re} \mathrm{v}}=\frac{\Delta \mathrm{p}}{\mathrm{J}_{\mathrm{c}} \eta_{\mathrm{ww}}}-\mathrm{R}_{\text {Irrev }}-\mathrm{R}_{\mathrm{M}} \quad\left[\mathrm{m}^{-1}\right]
$$

where $J_{c}$ is the flux at the end of the filtration and $\eta_{w w}$ is the viscosity of wastewater. The total resistance $\left(R_{T}\right)$ can be evaluated from the steady-state flux by using the resistance-in-series model:

$$
\mathrm{R}_{\mathrm{T}}=\mathrm{R}_{\mathrm{M}}+\mathrm{R}_{\text {Irrev }}+\mathrm{R}_{\mathrm{Rev}}\left[\mathrm{m}^{-1}\right]
$$

Fouling mechanisms were described with widely used filtration laws (complete pore blocking, gradual pore blocking, intermediate filtration and cake filtration) [44] to characterize membrane fouling.

\section{ACKNOWLEDGEMENTS}

This project was supported by the János Bolyai Research Scholarship of the Hungarian Academy of Sciences. The authors are grateful for the financial support provided by the project Hungarian Science and Research Foundation (NKFI contract number K112096). The authors are also grateful to Unichem Kft. for supporting our work by supplying the coagulant/flocculant materials for this study. 


\section{REFERENCES}

1. M. Padaki, R. Surya Murali, M.S. Abdullah, N. Misdan, A. Moslehyani, M.A. Kassim, N. Hilal, A.F. Ismail, Desalination, 2015, 357, 197.

2. P. Cañizares, F. Martínez, C. Jiménez, C. Sáez, M.A. Rodrigo, Journal of Hazardous Materials, 2008, 151, 44.

3. M. Gryta, K. Karakulski, A.W. Morawski, Water Research, 2001, 35, 3665.

4. J. Yin, J. Zhou, Desalination, 2015, 365, 46.

5. M. Matos, C.F. García, M.A. Suárez, C. Pazos, J. M. Benito, Journal of the Taiwan Institute of Chemical Engineers, 2016, 59, 295.

6. Y. Hu, Y. Zhu, H. Wang, C. Wang, H. Li, X. Zhang, R. Yuan, Y. Zhao, Chemical Engineering Journal, 2017, 322, 157.

7. J. Benito, G. Ríos, E. Ortea, E. Fernández, A. Cambiella, C. Pazos, J. Coca, Desalination, 2002, 147, 5.

8. A.B. Nordvik, J.L. Simmons, K. R. Bitting, A. Lewis, T. Strøm-Kristiansen, Spill Science \& Technology Bulletin, 1996, 3, 107.

9. A.A. Al-Shamrani, A. James, H. Xiao, Water Research, 2002, 36, 1503.

10. R. Zolfaghari, A. Fakhru'l-Razi, L.C. Abdullah, S.S.E.H. Elnashaie, A. Pendashteh, Separation and Purification Technology, 2016, 170, 377.

11. C. Wang, A. Alpatova, K.N. McPhedran, M. Gamal El-Din, Journal of Environmental Management, 2015, 160, 254.

12. E. Bazrafshan, F.K. Mostafapoor, M.M. Soor, A.H. Mahvi, Fresenius Environmental Bulletin, 2012, 21, 2694.

13. B. Chakrabarty, A.K. Ghoshal, M.K. Purkait, Journal of Membrane Science, 2008, 325, 427.

14. R.S. Souza, P.S.S. Porto, A.M.A. Pintor, G. Ruphuy, M.F. Costa, R.A.R. Boaventura, V.J.P. Vilar, Chemical Engineering Journal, 2016, 285, 709.

15. M. Abbasi, A. Salahi, M. Mirfendereski, T. Mohammadi, A. Pak, Desalination, 2010, 252, 113.

16. M. Cheryan, N. Rajagopalan, Journal of Membrane Science, 1998, 151, 1328.

17. C. Song, T. Wang, Y. Pan, J. Qiu, Separation and Purification Technology, 2006, $51,80$.

18. A. Salahi, A. Gheshlaghi, T. Mohammadi, S.S. Madaeni, Desalination, 2010, 262, 235.

19. H. Shokrkar, A. Salahi, N. Kasiri, T. Mohammadi, Chemical Engineering Research and Design, 2012, 90, 846.

20. F.L. Hua, Y.F. Tsang, Y.J. Wang, S.Y. Chan, H. Chua, S.N. Sin, Chemical Engineering Journal, 2007, 128, 169.

21. H. Ohya, J.J. Kim, A. Chinen, M. Aihara, S.I. Semenova, Y. Negishi, O. Mori, M. Yasuda, Journal of Membrane Science, 1998, 145, 1.

22. S.R.H. Abadi, M.R. Sebzari, M. Hemati, F. Rekabdar, T. Mohammadi, Desalination, 2011, 265, 222. 
23. K. Masoudnia, A. Raisi, A. Aroujalian, M. Fathizadeh, Desalination and Water Treatment, 2014, 55, 901.

24. Z.L. Kiss, L. Kocsis, G. Keszthelyi-Szabó, C. Hodúr, Z. László, Desalination and Water Treatment, 2014, 55, 3662.

25. X. Hu, Y. Yu, J. Zhou, Y. Wang, J. Liang, X. Zhang, Q. Chang, L. Song, Journal of Membrane Science, 2015, 476, 200.

26. J. Lindau, A.S. Jijnsson, Journal of Membrane Science, 1994., 87, 71.

27. B. Chakrabarty, A.K. Ghoshal, M.K. Purkait, Chemical Engineering Journal, 2010, 165, 447.

28. N. Moulai-Mostefa, O. Akoum, M. Nedjihoui, L. Ding, M.Y. Jaffrin, Desalination, 2007, 206, 494.

29. X.S. Yi, S.L. Yu, W. X. Shi, N. Sun, L.M. Jin, S. Wang, B. Zhang, C. Ma, L.P. Sun, Desalination, 2011, 281, 179.

30. L.Y. Susan, S. Ismail, B.S. Ooi, H. Mustapa, Journal of Water Process Engineering, 2017, 15, 55.

31. J. Zhang, Q. Xue, X. Pan, Y. Jin, W. Lu, D. Ding, Q. Guo, Chemical Engineering Journal, 2017, 307, 643.

32. Y.Z. Song, X. Kong, X. Yin, Y. Zhang, C.C. Sun, J.J. Yuan, B. Zhu, L.P. Zhu, Colloids and Surfaces A: Physicochemical and Engineering Aspects, 2017, 522, 585.

33. M.J. Um, S.H. Yoon, C.H. Lee, K.Y. Chung, J.J. Kim, Water Research, 2001, 35, 4095.

34. Y.G. Park, Desalination, 2002, 147, 43.

35. S.G. Lehman, L. Liu, Water Research, 2009, 43, 2020.

36. D. Metcalfe, P. Jarvis, C. Rockey, S. Judd, Separation and Purification Technology, 2016, 163, 173.

37. Z. Yang, B. Gao, B. Cao, W. Xu, Q. Yue, Separation and Purification Technology, 2011, 80, 59.

38. B.Y. Gao, Y.B. Chu, Q.Y. Yue, B.J. Wang, S.G. Wang, Journal of Environmental Management, 2005, 76, 143.

39. C. Hu, H. Liu, J. Qu, Colloids and Surfaces A: Physicochemical and Engineering Aspects, 2005, 260, 109.

40. C. Hu, H. Liu, J. Qu, D. Wang, J. Ru, Environmental Science and Technology, 2006, 40, 325.

41. W. Chen, J. Peng, Y. Su, L. Zheng, L. Wang, Z. Jiang, Separation and Purification Technology, 2009, 66, 591.

42. B. Van der Bruggen, Journal of Applied Polymer Science, 2009, 114, 630.

43. S. Kertész, Z. László, E. Forgács, G. Szabó, C. Hodúr, Desalination and Water Treatment, 2012, 35, 195.

44. B. Hu, K. Scott, Chemical Engineering Journal, 2008, 136, 210. 